\title{
What if houses were powered by milk?
}

\author{
Neil Phillips, Andrew Adamatzky, Richard Mayne \\ Unconventional Computing Centre, University of the West of England, Bristol, UK
}

\begin{abstract}
Living architectures and green energy are hot topics of the applied sciences. They aim to develop buildings that co-live with their environment and co-habit with people they house. An ultimate goal would be to make every block in a building capable of producing energy. We present results of scoping, and somewhat illustrative, experiments on generating electrical energy in modified aerated concrete blocks. These blocks are commonly used in modern building industry and therefore make an ideal candidate for 'inbuilt' microbial bio-reactors. We fill the blocks with milk to evaluate electro-generation potential of a pasteurised milk and to study power generating potential of the medium nutrient rich for micro-organisms. We assess the practicality of using bio-reactors which become colonised by local micro-flora.
\end{abstract}

Keywords: bio-reactor, milk, microbial fuel cells

So the girl ran further until she came to a river of milk flowing in banks of pudding. River of milk, banks of pudding, where did the swan-geese fly to?

"The Magic Swan-Geese" by A.N. Tolstoy

\section{Introduction}

Production of green and renewable energy is amongst top priorities of the world governments $[1,2,3]$. Microbial fuel cell technology is so far most perspective a par with solar and green energy productions $[4,5,6,7]$. Microbial bioelectricity is considered to be a lowcarbon, low-cost, sustainable potential energy solution for both developed and developing nations $[8,9]$. Bio-reactors are based on the operational principles of microbial communities. The self-governing nature of microbial communities means they are able to adapt to conditions to maintain system efficiencies by adjusting consortia. Despite having many functions, bio-reactors have recently been realised as a potential source of electricity generation: micro-organisms are cultivated in a chamber (anodic) containing aqueous media and an electrode. A second, abiotic (cathodic) electrode-containing chamber is connected to the first via a semi-permeable membrane which permits the flow of hydrogen ions $\left(\left[\mathrm{H}^{+}\right]\right)$. Microbes in the anodic chamber catabolise a supplied food source, which may be any readily-oxidised organic substrate, which liberates electrons and $\left[\mathrm{H}^{+}\right]$. If the anodic chamber is anaerobic, the anode becomes an electron acceptor, generating a small electrical current, creating an electrochemical gradient which drives the transport of $\left[\mathrm{H}^{+}\right]$through the semi-permeable membrane $[4,5,10]$. 
Despite fast advances of technology power output of microbial fuel cells utilising biological material and waste is still modest $[11,12,13]$. A solution could be to integrate fuel cells inside the buildings en mass where every brick or every building block is a microbial fuel cells. Such an approach well integrates in the living architecture aimed to produce buildings which co-live with their environemnt, co-habit with their occupants, and integrate living creatures and their artificial counterparts $[14,15,16]$.

To make a first step towards production of buildings made of microbial fuel cells we undertook a range of scoping experiments by making fuel cells from aerated concrete blocks [17] and filling them with cow milk. Results of the experiments are reported in present paper.

Why choose milk? Our motive was two-fold. First, to play an improvable scenario where European Common Agricultural Policy (CAP) - aimed to curb overproduction of milk and reduce budgetary deficit — will be lifted (because it is failed to achieve desirable economic effects anyway [18]). And, the cow milk will be an abundant commodity in Europe, and thus will become the cheapest potential precursor of bioenergy [19, 20]. Second, to evaluate electro-generation potential of a pasteurised milk. Milk is a weakly acidic colloid containing lipids (predominantly triacylglycerols), proteins and enzymes, polysaccharides (lactose, glucose, galactose) and various salts and minerals such as calcium. As such it is a rich nutrient medium for micro-organisms: raw milk typically supports complex microflora including Lactobacillus spp., Streptococcus spp., Bifidobacterium spp. and Enterococcus spp. [21, 22]. Pasteurisation is employed to greatly reduce or completely remove all microbes which would "spoil" the milk — via catabolism of desirable components such as sugars and anabolism of undesirable compounds - as well as potentially pathogenic organisms such as coliforms $[23,24,25]$.

Why were aerated blocks chosen? Aerated (foamed) concrete was invented in the 1920's with properties that are advantageous for constructing buildings [26, 27, 28]: (a) typical compressive strength of $3.6 \mathrm{~N} / \mathrm{mm}^{2}$ means it can be used throughout multi-storey buildings, including solid walls, beam and block flooring systems, foundations, internal and external leaf of cavity walls, separation walls and partitions [17]; (b) highly thermally insulating; (c) porous structure allows for superior fire resistance; (d) workability allows accurate cutting; (e) non-toxic (no toxic gases or other toxic substances in autoclaved aerated concrete); (f) long lasting (it will not degrade under normal climate changes). Aerated cement blocks are "Semi-porous materials with open pores always include a certain percentage of moisture that affects their physical, thermal, and mechanical properties" [29]. The typical chemical composition of aerated cement is [30]: sand which contains more than $85 \%$ silica and clay (aluminium silicates); aluminium powder/paste; lime which contains $75 \%$ calcium oxide; silicon dioxide; dehydrate or phosphogypsum which contains sulfur trioxide; portland cement (calcium silicate and calcium aluminate). The properties of aerated cement blocks are conducive to the construction of bio-reactors as they can form both semi-permeable membrane(s) between chambers and the main body of the bio-reactors. These properties minimises part count which in turn reduces cost and simplifies assembly.

The paper is structured as follows. Experimental setup is introduced in Sect. 2. Section 3 presents results of aerobic experiments without (Sect. 3.1) and with electrical load (Sect. 3.2), and anaerobic experiments with electrical load (Sect. 3.3). Practicality of the approach is 


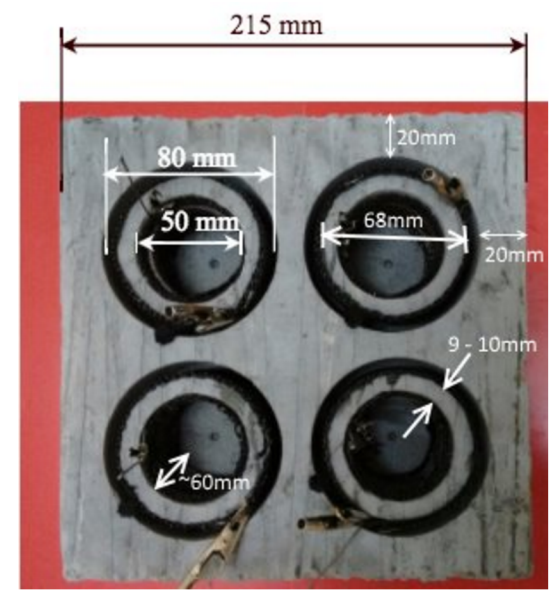

Figure 1: Aerobic setup. View of the concrete block with four bio-reactors.

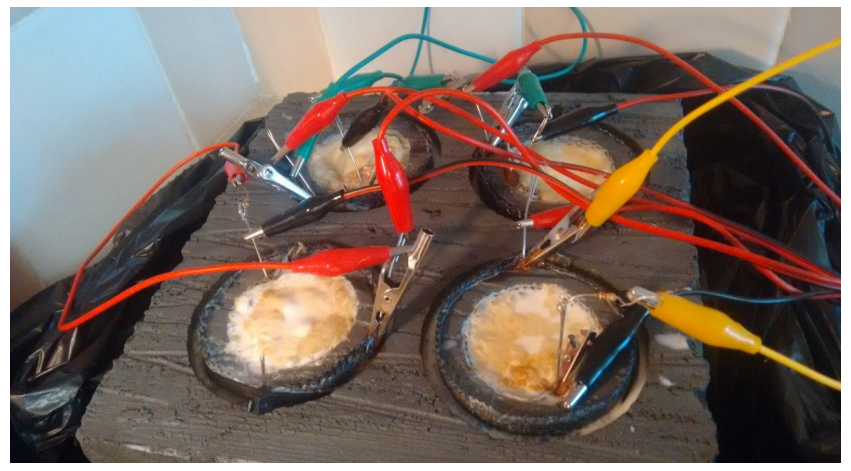

Figure 2: Photo of one block with four aerobic bio-reactors each, in the process of recording electrical potential of the cells.

discussed in Sect. 4.

\section{Methods}

Microbial bio-reactors have been made inside Celcon standard aerated blocks $(440 \mathrm{~mm}$ long, $215 \mathrm{~mm}$ wide and $100 \mathrm{~mm}$ deep) [17] (Fig. 1) were made using a standard pillar drill (rated power of $500 \mathrm{~W}$ ) with three bits in the following order: (a) Drill a $55 \mathrm{~mm}$ deep slot with $80 \mathrm{~mm}$ diameter core bit; (b) Drill a $60 \mathrm{~mm}$ deep slot with $50 \mathrm{~mm}$ dia core bit; (c) Drill a $60 \mathrm{~mm}$ deep hole with $40 \mathrm{~mm}$ diameter hinge bit. The drilling speed was $250 \mathrm{rpm}$ with vacuum dust extraction. Thus each bio-reactor consisted of an inner cylinder (volume $118 \mathrm{~mL}$ ) with a wall circa $9.5 \mathrm{~mm}$ thick embedded into an outer cylinder (volume $276 \mathrm{~mL}$ ). Volume of inner chamber was $118 \mathrm{~mL}$ and the outer chamber $123 \mathrm{~mL}$. Electrodes were formed from $50 \mathrm{~mm}$ wide, plain weave, carbon fibre tape $\left(200 \mathrm{~g} / \mathrm{m}^{2}\right)$ [31]. The reference electrode was wrapped inside internal cylinder and the recording electrode inside outer cylinder. In experiments with load the $100 \mathrm{Ohm}$ resistor was attached between the recording electrodes to make a power load (Fig. 2). 


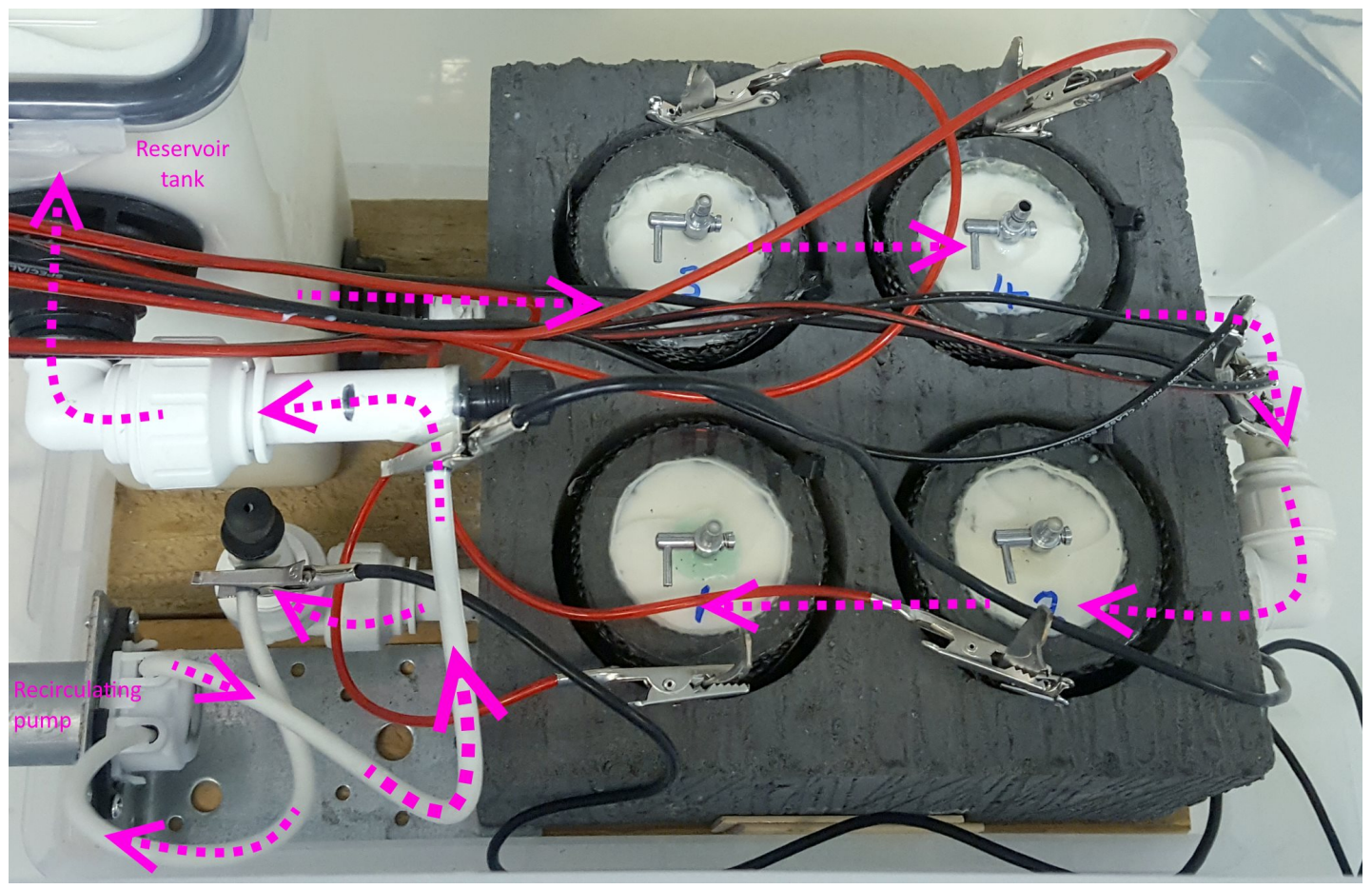

Figure 3: Photo of anaerobic setup.

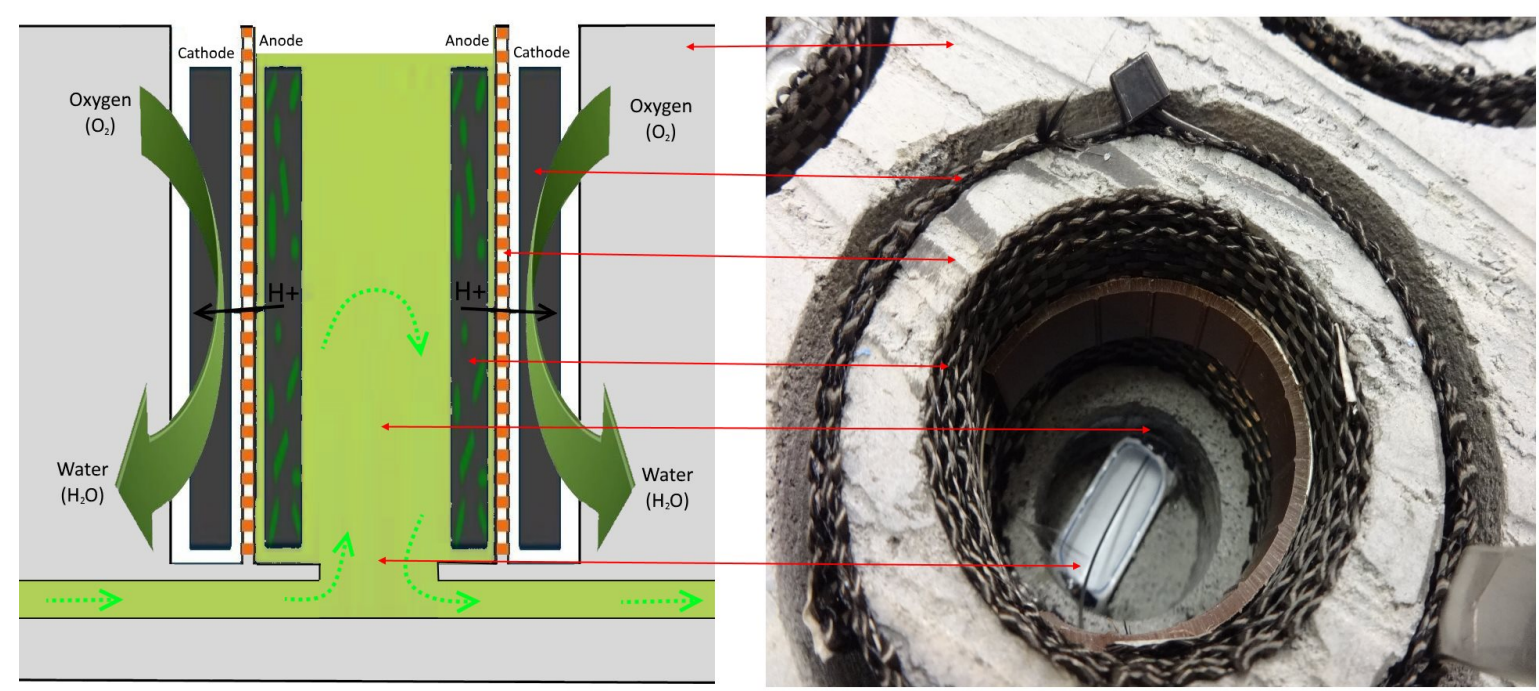

Figure 4: Close up of transfer part in the single bio-reactor in anaerobic setup. 


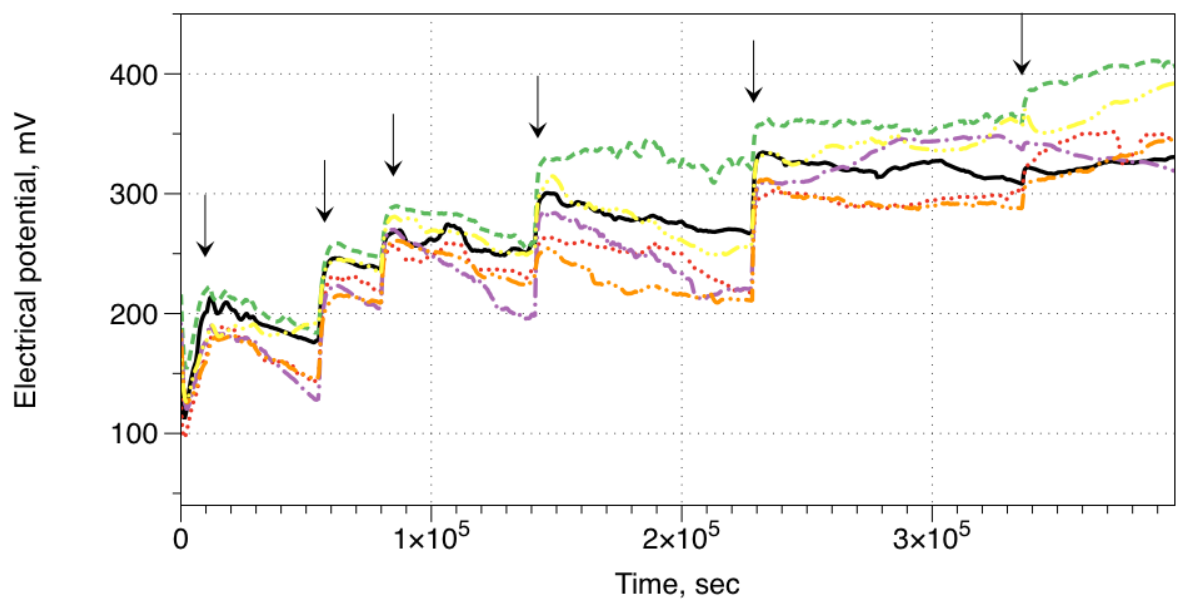

Figure 5: Dynamics of open circuit (no load), electrical potential difference in bio-reactors recorded over six days. Data from six exemplar bio-reactors are coded by colour and style. Moments when more milk is added to cells are shown by arrows.

In a separate series of experiments, all anodic chambers were sealed to air in order to create an anaerobic environment (Fig. 3); the purpose of this was to compare power generation of both aerbocially and anaerobically-respiring organisms. The aerated concrete blocks were modified as follows in order to seal them (Fig. 3): the anodic chambers were connected (in series) via $15 \mathrm{~mm}$ dia plastic tubing and the open tops of the inner cylinders were sealed with Perspex covers, containing air bleed valves (Fig. 4). The anodic chambers were connected to reservoir tank (of 2 litres capacity and integrated air bleed valve) via flexible plastic piping and recirculation pump. The flow-rate through the D4 peristaltic pump was nominally $50 \mathrm{ml} / \mathrm{min}$ by setting the pump supply voltage to $9 \mathrm{~V}$ DC.

We recorded the electrical potential difference between reference and recording electrodes using PICO ADC-24 USB data logger [32] with the sampling rate one sample per second (for each sample the logger made c. 1000 measurements, averaged over one second). The recording was done continuously over several days. The inner and outer cylinders were filled with milk (Tesco British Whole Milk). The milk was topped up periodically; the moments of top ups are shown on the plots. The setup was kept in room temperature of $18^{\circ} \mathrm{C}$ with dim ambient lighting.

\section{Results}

\subsection{Aerobic setup. No load}

The electrical potential difference between the compartments becomes c. $100 \mathrm{mV}$ and then growth over several hours to c. $200 \mathrm{mV}$; see exemplar dynamics of electrical potential difference in Fig. 5. Then milk becomes partly absorbed by the block and thus the volume of milk in the chamber decreases. This is associated with a decrease in the electrical potential difference. When the milk is topped-up in all chambers of all cells the potential difference 


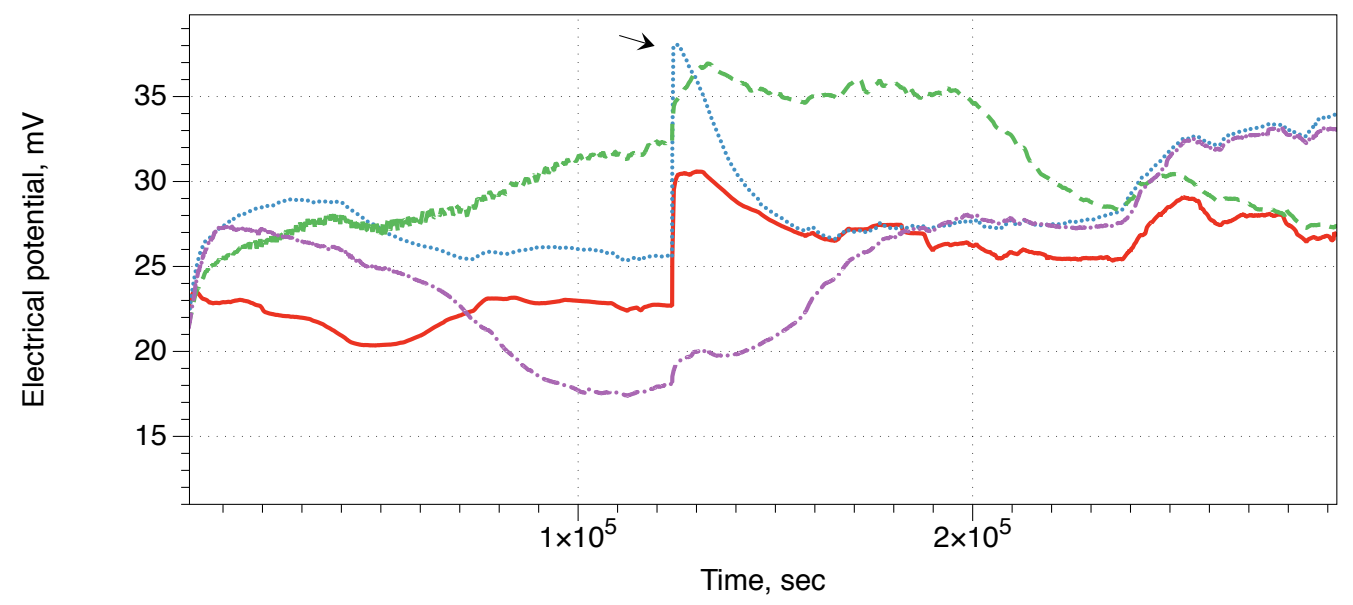

Figure 6: Dynamics of electrical potential difference in bio-reactors with $100 \mathrm{Ohm}$ load recorded over four days. Data from four exemplar bio-reactors are coded by colour and style. Moments when more milk is added to cells are shown by arrows. Moment when more milk is added to a central/inner chamber is shown by arrow.

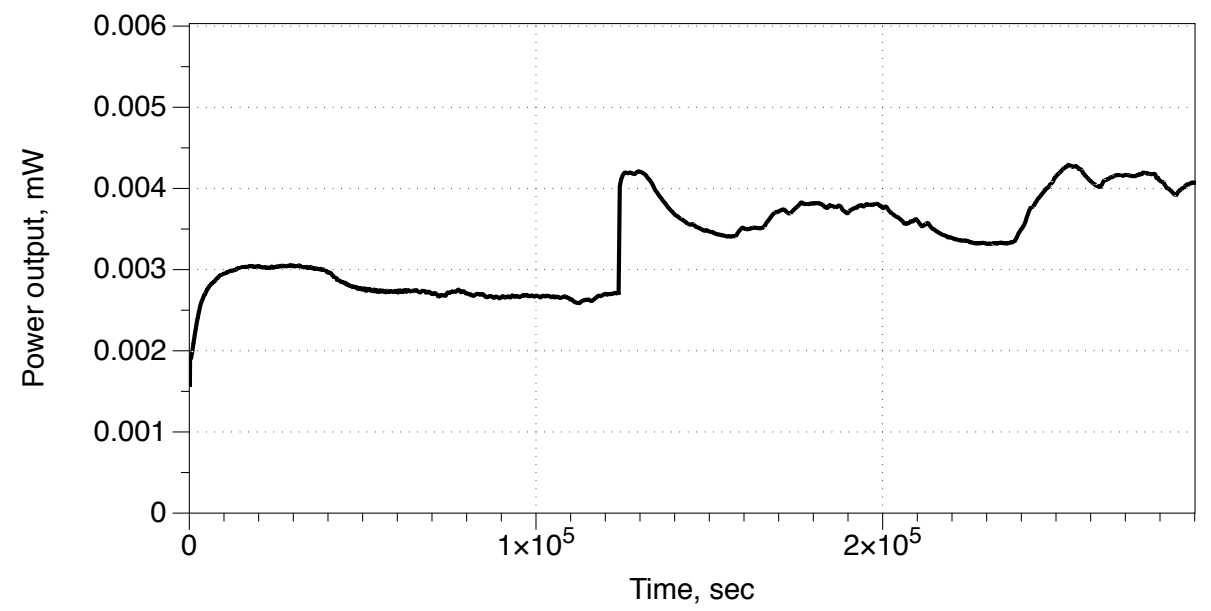

Figure 7: Average power output (mW) of bio-reactors, in aerated cement block, with $100 \mathrm{Ohm}$ load (across electrodes).

between chambers in each cell increases to c. 200-250 mV (Fig. 5). After 12 hours a fermentation of milks starts in the cells. This is associated with further increase in the potential difference. Less top-ups is required after 30-35. The maximal (over cells) potential grows from initial $100 \mathrm{mV}$ to maximum $420 \mathrm{mV}$ over 6 days. Average potential (over all cells and time of recording) is $295 \mathrm{mV}$ with standard deviation $28 \mathrm{mV}$.

\subsection{Aerobic setup. 100 Ohm load}

Electrical potential of bio-reactors with $100 \mathrm{Ohm}$ shows less variability than non-loaded bio-reactors (Fig. 6). Typical potential at the beginning of experiments is c. $24 \mathrm{mV}$ which 


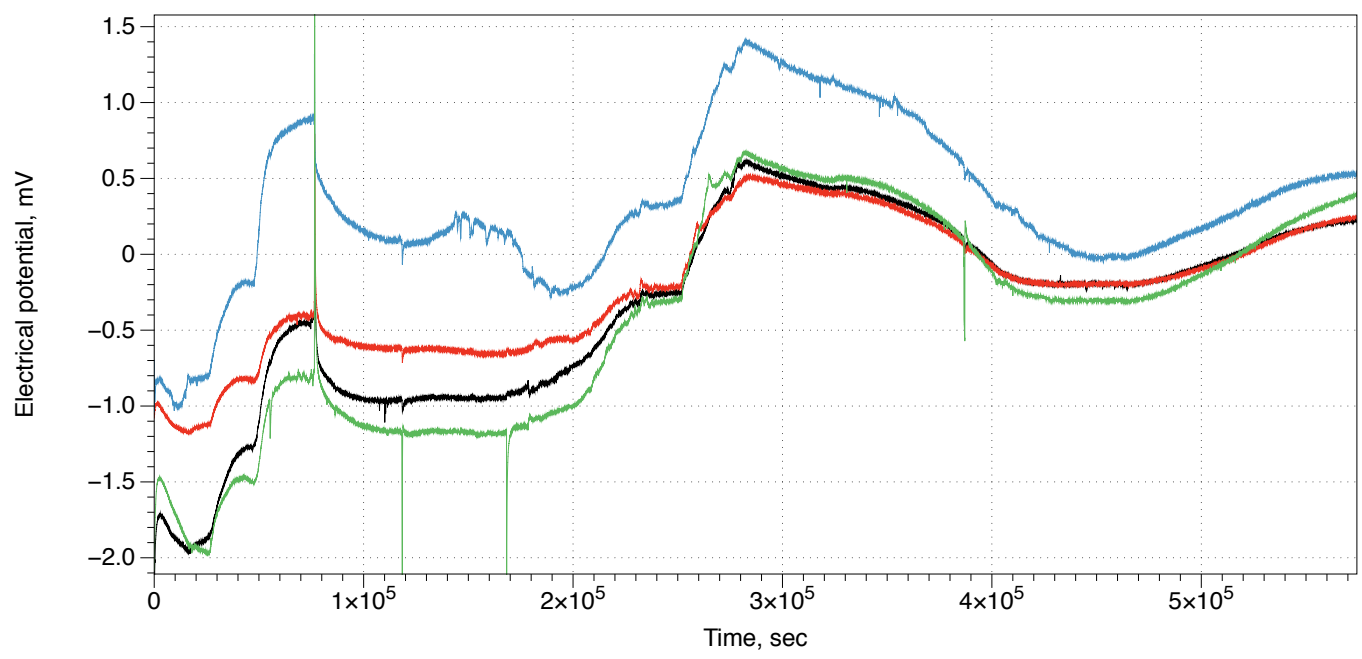

Figure 8: Anaerobic setup. Dynamics of electrical potential difference in anaerobic bio-reactors with 100 Ohm load. Data from four exemplar bio-reactors are coded by colour and style.

grows up to $37 \mathrm{mV}$. The potential shows a drastic increase in value when milk is topped up at, (shown by arrow in Fig. 6. The potential reaches its maximum typically after 35-40 hours (Fig. 6), then shows are slow decline. Corresponding dynamics of power generation is shown in Fig. 7. Highest average output achieved is $4 \mu \mathrm{W}$, with the output $3 \mu \mathrm{W}$ guaranteed. Exactly, average over bio-reactors and run times output is $3.3 \mu \mathrm{W}$ with standard deviation 0.00055 .

\subsection{Anaerobic experiments}

We recorded the electrical potential difference between the cathode and anode electrodes using PICO ADC-24 USB data logger [16]. The recording was done continuously over 6 days with the sampling rate one sample per second. All the inner anodic chambers were filled with milk (Tesco British Whole Milk) which was continuously re-recirculated around the anodic chambers and the reservoir tank by D4 peristaltic pump. The initial flow rate was circa $50 \mathrm{ml}$ per minute which dropped as the milk congealed. The cathodic chambers were left empty and open to atmosphere. The setup was kept in room temperature of $22^{\circ} \mathrm{C}$ with ambient lighting.

The electrical output from anaerobic bio-reactors with $100 \mathrm{Ohm}$ load was significantly lower than comparable bio-reactors that were left open to air, with output voltage typically being in the region of an order of magnitude smaller (Fig. 8).

\section{Discussion}

A key focus of this study was to assess the practicality of using bio-reactors which become colonised by local micro-flora, as opposed to using exogenous cultures which necessitate purification and depathogenation (e.g. cultures from activated sludge), as this latter requirement is not ideal for certain prospective uses of this technology, such as in third 
world countries. On the other hand, and as our results indicate, allowing colonisation of the nutrient substrate by opportunistic microbes limits the repeatability of these experiments, both between batches and locations; for example, the microbes present in a laboratory's air circulation system will differ from those present in the average household. We therefore recommend that investigation into which microbes inhabit milk bio-reactors is a route towards their further development.

The microflora present within houses constructed with fuel cell bricks is likely to be variable between populations and geographical locations, however, which may result in significant variability in the efficiency of microbial metabolism. An alternative method to increase repeatability would be to introduce a starter culture containing a microbe species known to thrive in the medium, such as pellets of dried yeast (Saccharomyces cerevisiae) or active Lactobacillus spp. colonies from active yoghurts.

If desirable, the liquid can easily be aerated with the ambient air through the use of a low pressure (aquarium) air compressor (circa 2 litres/minute, 20kPa) and air stone. This will ensure that the liquid is thoroughly exposed to airborne microorganisms in the vicinity.

The initial set-up was an artificial construction designed to trial a potential real life configuration. It was felt important to explore the performance of a low cost configuration which could be easily adopted if beneficial. Therefore, the configuration was not sterilized or indoctrinated with a selected organism. System sterilization is unlikely to be practical in some cases due to logistical issues (access to all parts) and cost. Further, flushing the system could make re-initiating difficult. To compound the challenge, the system may need to operate on contaminated growth media. Non lab based testing (beyond that reported) has indicated that contamination by ambient microflora occurs unless stringent prevention protocols are implemented. In practice, using a growth media optimized for the desired species and following basic isolation protocols is not sufficient to prevent contamination over a prolonged period. Consequently, a low cost implementation would need to be able to accommodate mixed species while maintaining acceptable system performance.

An average four bedroom bungalow can be built from c. 4000 aerated concrete blocks. Each block could have eight bio-reactors, therefore assuming milk is circulated through the blocks of the bungalow's walls such a house can generate $0.096 \mathrm{~W}$. Whilst a single milk bio-reactor does not show a substantial power output it is still a feasible candidate for energy neutral building, especially in the context of agricultural farming facilities where over-production of milk might occur.

The finding that anaerobic bio-reactors produce significantly less power than open-to-air bio-reactors was somewhat surprising, given that aerobic respiration does not produce free $\left[\mathrm{H}^{+}\right]$. We propose that the reasons for this were twofold: firstly, being hermetically sealed caused the milk in anaerobic bio-reactors to separate out very rapidly which, due to the effects of being pumped, caused all solid matter to deposit in the reservoir tank rather than the bio-reactors, thus limiting the nutrients available in the active components of the bioreactor. Secondly, the open-to-air bio-reactors were subject to a greater degree of exposure to environmental microbes which likely encouraged the development of more complex cultures; as there was only a small area in each bio-reactor that was open to the air, a high-enough rate of microbial metabolism likely contributed to the generation of anaerobic zones in the 
underlying fluid. This result is somewhat enthusing, however, as from a practical perspective it is easier to fabricate and maintain open-to-air bio-reactors than fully-sealed systems, thus demonstrating an advantage of this minimalistic, frugal technology.

\section{Acknowledgement}

The work was partially supported by European Commission Horizon2020 FET-OPEN grant 686585 to the Living Architecture (LIAR) project [4]. The project aims to design and build the next generation of buildings.

\section{References}

[1] V. Lauber, S. Jacobsson, The politics and economics of constructing, contesting and restricting sociopolitical space for renewables-the german renewable energy act, Environmental Innovation and Societal Transitions 18 (2016) 147-163.

[2] J. Broome, D. K. Foley, A world climate bank, Institutions For Future Generations (2016) 156.

[3] H. J. Schellnhuber, S. Rahmstorf, R. Winkelmann, Why the right climate target was agreed in paris, Nature Climate Change 6 (7) (2016) 649-653.

[4] R. M. Allen, H. P. Bennetto, Microbial fuel-cells, Applied biochemistry and biotechnology 39 (1) (1993) 27-40.

[5] B. E. Logan, B. Hamelers, R. Rozendal, U. Schröder, J. Keller, S. Freguia, P. Aelterman, W. Verstraete, K. Rabaey, Microbial fuel cells: methodology and technology, Environmental science \& technology 40 (17) (2006) 5181-5192.

[6] B. E. Logan, Microbial fuel cells, John Wiley \& Sons, 2008.

[7] K. Rabaey, W. Verstraete, Microbial fuel cells: novel biotechnology for energy generation, TRENDS in Biotechnology 23 (6) (2005) 291-298.

[8] B. K. Behera, A. Varma, Microbial resources for sustainable energy (2016).

[9] S. V. Mohan, G. Nikhil, P. Chiranjeevi, C. N. Reddy, M. Rohit, A. N. Kumar, O. Sarkar, Waste biorefinery models towards sustainable circular bioeconomy: critical review and future perspectives, Bioresource technology 215 (2016) 2-12.

[10] E. Yu, K. Scott, Low cost materials for the air cathodes in single-chamber microbial fuel cells: A mini review.

[11] D. Pant, G. Van Bogaert, L. Diels, K. Vanbroekhoven, A review of the substrates used in microbial fuel cells (mfcs) for sustainable energy production, Bioresource technology 101 (6) (2010) 1533-1543.

[12] M. Sun, L.-F. Zhai, W.-W. Li, H.-Q. Yu, Harvest and utilization of chemical energy in wastes by microbial fuel cells, Chemical Society Reviews 45 (10) (2016) 2847-2870.

[13] L. Xu, Y. Zhao, L. Doherty, Y. Hu, X. Hao, The integrated processes for wastewater treatment based on the principle of microbial fuel cells: A review, Critical Reviews in Environmental Science and Technology 46 (1) (2016) 60-91.

[14] P. Beesley, Can architecture embody living systems? emerging livingtechnologies and synthetic biology, arq: Architectural Research Quarterly 20 (2) (2016) 92-94.

[15] R. Armstrong, An experimental approach towards architectural ecologies, Systema: connecting matter, life, culture and technology 3 (2) (2015) 91-113.

[16] R. Armstrong, Design scrying: an alternative aesthetics for synthetic biology, Architectural Research Quarterly 20 (01) (2016) 29-38.

[17] Celcon block standard grade, www.hhcelcon.co.uk/solutions/by-product/celcon-block-standard-grade, accessed: 2016-12-22.

[18] F. Ang, A. O. Lansink, Decomposing dynamic profit inefficiency of belgian dairy farms.

[19] U. N. E. P. B. W. Group, U. N. E. P. I. P. for Sustainable Resource Management, Towards sustainable production and use of resources: assessing biofuels, UNEP/Earthprint, 2009. 
[20] N. D. Clarke, Protein engineering for bioenergy and biomass-based chemicals, Current opinion in structural biology 20 (4) (2010) 527-532.

[21] A. M. Gomes, F. X. Malcata, Bifidobacterium spp. and lactobacillus acidophilus: biological, biochemical, technological and therapeutical properties relevant for use as probiotics, Trends in Food Science \& Technology 10 (4) (1999) 139-157.

[22] E. Franciosi, L. Settanni, A. Cavazza, E. Poznanski, Biodiversity and technological potential of wild lactic acid bacteria from raw cows' milk, International dairy journal 19 (1) (2009) 3-11.

[23] T. Kudra, C. Strumillo, Thermal processing of bio-materials, Vol. 10, CRC Press, 1998.

[24] J. Van Kessel, J. Karns, L. Gorski, B. McCluskey, M. Perdue, Prevalence of salmonellae, listeria monocytogenes, and fecal coliforms in bulk tank milk on us dairies, Journal of Dairy Science 87 (9) (2004) 2822-2830.

[25] M.-L. Ackers, S. Schoenfeld, J. Markman, M. G. Smith, M. A. Nicholson, W. DeWitt, D. N. Cameron, P. M. Griffin, L. Slutsker, An outbreak of yersinia enterocolitica o: 8 infections associated with pasteurized milk, Journal of Infectious Diseases 181 (5) (2000) 1834-1837.

[26] J. Alexanderson, Relations between structure and mechanical properties of autoclaved aerated concrete, Cement and Concrete Research 9 (4) (1979) 507-514.

[27] H. Kurama, I. Topcu, C. Karakurt, Properties of the autoclaved aerated concrete produced from coal bottom ash, Journal of materials processing technology 209 (2) (2009) 767-773.

[28] N. Narayanan, K. Ramamurthy, Structure and properties of aerated concrete: a review, Cement and Concrete Composites 22 (5) (2000) 321-329.

[29] R. Drochytka, J. Zach, A. Korjenic, J. Hroudová, Improving the energy efficiency in buildings while reducing the waste using autoclaved aerated concrete made from power industry waste, Energy and Buildings 58 (2013) 319-323.

[30] R. Malhotra, Autoclaved aerated concrete, chemistryofmaterials2013.wikidot.com/rahul-malhotra, accessed: 2016-12-22.

[31] Carbon fibre 200g plain weave 3k 1m wide, www .composites4u.co.uk/Carbon-Fibre-200g-Plain-Weave-3k-1m-Wid accessed: 2016-12-11.

[32] High-resolution data acquisition, https://www.picotech.com/data-logger/adc-20-adc-24/precision-data-acqu accessed: 2016-12-11. 